\title{
Placement of SVC for Multi-objective Function using RCGA
}

\author{
Ankita Singh \\ Department of Electrical Engineering \\ Madhav Institute of Tech. \& Sc \\ Gwalior, India
}

\author{
Shishir Dixit \\ Department of Electrical Engineering \\ Madhav Institute of Tech. \& Sc \\ Gwalior, India
}

\begin{abstract}
This paper addresses the optimal placement of static var compensators (SVCs) in a power system network in such a manner that power loss, voltage deviation and installation cost is minimized. Voltage deviation is minimized by improving voltage profile. The aim of this study is to minimizing the power loss, voltage deviation and installation cost under critical contingency and increasing load condition in power system network. The multi-objective function is carried out in this study. RCGA is used to solve the optimization problem in this paper which is one of the heuristic methods. Real Coded Genetic Algorithm optimization helps in determining the location of the SVC. The proposed approach has been tested on IEEE-30 Bus test system with different objectives. It has also been observed, we can apply this algorithm to larger systems with computational difficulties. The obtained results show that the suggested method of SVC placement is effective in reducing the real power loss, voltage deviation and installation cost during normal as well as critical contingency cases.
\end{abstract}

\section{General Terms}

Power Loss, SVC, Critical Contingency, Real Coded Genetic Algorithms.

\section{Keywords}

FACTS devices, Genetic Algorithm, SVC, Voltage Profile, Voltage deviation, Power Loss, Installation Cost.

\section{INTRODUCTION}

FACTS (Flexible Alternating Current Transmission System) play a vital role in the emerging power system in enhancing the system stability by several factors. They are generally based on power electronics which is used for increasing transmission capacity in power system. They also have the capacity to control several parameters in transmission network. FACTS devices can enhance the stability of power system network and can support voltage with better controllability of their parameters like impedance, current, voltage etc [1]. FACTS have the capability to increase the reliability of power system networks and enhance power flow control of the system. These devices are popularly used for enhancing the overall performance of a power system. The systems performance has improved by appropriate location and sizing of the FACTS controllers. SVC is selected as the placement and sizing in the power system network. SVC reacts very fast and has high reliability as compared to mechanically switched capacitor banks. Static var compensator (SVC) is capable of effectively controlling the voltage profile by adjusting the reactive power at the point of connection. Among other FACTS controllers, SVC is more popular because its cost is low as compared to the other devices. This paper focuses on enhancement of the system performance under contingency through an optimal placement and optimal setting of SVC. There are several methods have been suggested to optimally locate these controllers in the system. In this paper, Genetic Algorithm is used to optimize the placement and sizing of FACTS devices in order to minimize the power loss, voltage deviation and installation cost of the System [2].

\section{FLEXIBLE AC TRANSMISSION SYSTEM (FACTS)}

FACTS devices are used for enhancement of power system stability and other various parameters. They primarily provide voltage support to the system when connected in shunt and regulate the power flow in lines when connected in series. Therefore by the use of combined series shunt controllers, we can achieve the both voltage and power flow control. There are various methods to connect the FACTS devices such as in series, shunt, series-series and series-shunt. The devices of series controllers are SSSC, TCSC etc. STATCOM, SVC, TCR, TSR, TSC, and TCBR are the members of shunt FACTS family. SVC is used in this study for minimizing the power loss, voltage deviation and installation cost.

\section{STATIC VAR COMPENSATOR (SVC)}

\subsection{Basic structure}

All SVC is a first generation FACTS controller. It is a variable impedance device in which the current through reactor is controlled by back to back connected thyristors. To exchange capacitive or inductive current its output is adjusted to maintain or control specific power variable typically, the control variable is the SVC bus voltage. It provides fast reactive power and voltage regulation support. The location of SVC is important in determining its effectiveness [3]. Thyristor switched capacitors and thyristor controlled reactors (TCR) are connected in parallel with the power system. One of the other main reasons for installing a SVC is to minimize voltage deviation and thus increase voltage profile of the system. The cost of SVC is lower than STATCOM. In solving voltage regulation, applications of static var compensator are used. The suitable control of this equivalent reactance allows voltage magnitude regulation at the SVC point of connection [4]. It injects reactive power into the system if QSVC $<0$ and absorbs reactive power from the system if QSVC >0[4]. It is modeled as a generator or absorber of reactive power. The schematic diagram of such SVC system has been shown in Figure.1 [5][6]. 


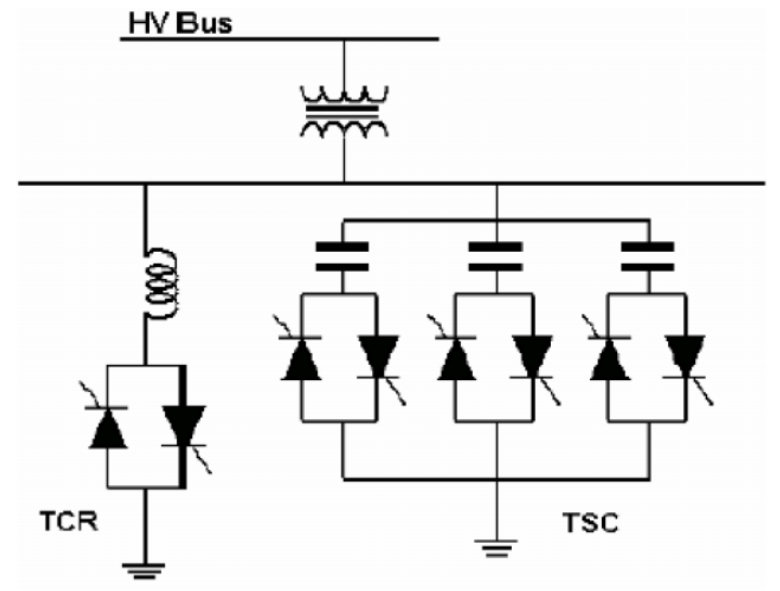

Fig 1: Basic structure of SVC

\subsection{Modeling of SVC}

The SVC is a combination of a fixed capacitors and reactors. It can be used for both inductive and capacitive compensation. The objective of SVC is to maintain the desired voltage at a high voltage bus. The SVC can be operated at both inductive and capacitive compensation [7]. The reactive power generated by SVC is shown by equation (1).

$$
\text { QMIN } \leq \mathrm{Q} \leq \mathrm{QMAX}
$$

\section{PROBLEM FORMULATION}

This is a multi-objective optimization function and the objective of this paper is to find simultaneously the optimal location and sizing of FACTS controllers so as to minimize the power loss, voltage deviation and installation cost. It is defined as the sum of minimization of power loss, voltage deviation and installation cost under contingency and increasing load condition. Therefore, it is multi-objective constrained optimization problem and formulated by the equation (3).

$$
F=w 1 f 1+w 2 f 2+w 3 f 3
$$

Where,

$\mathrm{F}$ is sum of power loss, load bus voltage deviation and cost of installation,

$\mathrm{w}_{1}, \mathrm{w}_{2}$ and $\mathrm{w}_{3}$ are the weight coefficient for power loss, voltage deviation and installation cost.

\subsection{Power Loss}

The second objective $f_{1}$ of this work is to minimize the power loss to determine the optimal location of SVC in the power system. The real power loss is calculated by the equation (3).

$\mathrm{P}_{\mathrm{L}}=\sum\left[\mathrm{V}_{\mathrm{i}}^{2}+\mathrm{V}_{\mathrm{j}}^{2}-2 \mathrm{~V}_{\mathrm{i}} \mathrm{V}_{\mathrm{j}} \cos \left(\delta_{\mathrm{i}}-\delta_{\mathrm{j}}\right) \mathrm{J}_{\mathrm{ij}} \cos \varphi_{\mathrm{ij}}\right.$

Where

$\mathrm{V}_{\mathrm{i}}$ is the voltage magnitude at bus $\mathrm{i}$,

$Y_{i j}$ is the magnitude of the admittance of the line from bus $i$ to bus j.

\subsection{Voltage deviation}

Voltage deviation is the first objective function and it is defined as a measure for the quality of service. By observing the minimum value of voltage deviation, optimal location SVC can be determined. Hence, the voltage deviation of the buses is calculated by the equation (4).

$$
\mathrm{VD}=\sum_{\mathrm{i}=1}^{\mathrm{b}}\left|\left(\mathrm{V}_{\mathrm{iref}}-\mathrm{V}_{\mathrm{i}}\right)\right|
$$

Where,

$\mathrm{b}$ is the number of buses,

$\mathrm{V}_{\text {iref }}$ is the reference voltage,

$\mathrm{V}_{\mathrm{i}}$ is the actual voltage.

\subsection{Installation Cost}

The second objective function $\mathrm{f}_{3}$ is the installation cost of SVC. The optimal placement and sizing of FACTS device considering the installation cost of FACTS device has been mathematically formulated and it has been calculated by the equation (5)

$$
\mathrm{C}_{\mathrm{SVC}}=\sum_{\mathrm{k}=1}^{\mathrm{n}} 0.0003 \mathrm{Q}^{2}-0.3051 \mathrm{Q}+127.38(\mathrm{US} \$ / \mathrm{kVAr})
$$

Where,

$\mathrm{Q}$ is the reactive power capacity of $\mathrm{k}^{\text {th }} \mathrm{SVC}$ in MVar[8].

\subsection{Equality constraints}

The power flow balance equations are represent by the equality constraints which are as follows:

$\mathrm{P}_{\mathrm{Gi}}-\mathrm{P}_{\mathrm{Li}}=\mathrm{V}_{\mathrm{i}} \sum_{\mathrm{k}=1}^{\mathrm{n}}\left(\mathrm{V}_{\mathrm{k}}\left[\mathrm{G}_{\mathrm{ik}} \cos \left(\theta_{\mathrm{i}}-\theta_{\mathrm{k}}\right)+\mathrm{B}_{\mathrm{ik}} \sin \left(\theta_{\mathrm{i}}-\theta_{\mathrm{k}}\right)\right]\right)$

$\mathrm{Q}_{\mathrm{Gi}}-\mathrm{Q}_{\mathrm{Li}}=\mathrm{V}_{\mathrm{i}} \sum_{\mathrm{k}=1}^{\mathrm{n}}\left(\mathrm{V}_{\mathrm{k}}\left[\mathrm{G}_{\mathrm{ik}} \sin \left(\theta_{\mathrm{i}}-\theta_{\mathrm{k}}\right)+\mathrm{B}_{\mathrm{ik}} \cos \left(\theta_{\mathrm{i}}-\theta_{\mathrm{k}}\right)\right]\right)$

Where,

$\mathrm{P}_{\mathrm{Gi}}$ and $\mathrm{Q}_{\mathrm{Gi}}$ are the generated active and reactive powers at node $\mathrm{i}$,

$\mathrm{P}_{\mathrm{Li}}$ and $\mathrm{Q}_{\mathrm{Li}}$ are the load active and reactive powers at node $\mathrm{i}$, $\mathrm{G}_{\mathrm{ik}}, \mathrm{B}_{\mathrm{ik}}$ are the conductance and susceptance.

\subsection{Inequality constraints}

The power flow limit and bus voltage limits are represented by the inequality constraints which are as follows:

$$
\mathrm{S}_{\mathrm{I}} \leq \mathrm{S}_{\mathrm{Imax}}
$$


Where,

$\mathrm{S}_{1}$ max is the thermal limit of the line or bus in steady-state operation.

$$
\mathrm{V}_{\text {imin }} \leq \mathrm{V}_{\mathrm{i}} \leq \mathrm{V}_{\text {imax }}
$$

Where,

$\mathrm{V}_{\mathrm{i}}$ is the bus voltages which must be maintained around the nominal value [9].

\subsection{Generation Constraints}

The generators constant for generator voltages, real power output and reactive power output are restricted by their lower and upper limit which are given as follows:[10]

$$
\begin{aligned}
& \mathrm{V}_{\mathrm{Gi}}{ }^{\text {min }} \leq \mathrm{V}_{\mathrm{Gi}} \leq \mathrm{V}_{\mathrm{Gi}}{ }^{\text {max }} \quad \mathrm{i}=1, \ldots . \mathrm{NG} \\
& \mathrm{P}_{\mathrm{Gi}}{ }^{\min } \leq \mathrm{P}_{\mathrm{Gi}} \leq \mathrm{P}_{\mathrm{Gi}}{ }^{\max } \quad \mathrm{i}=1, \ldots . \mathrm{NG} \\
& \mathrm{Q}_{\mathrm{Gi}}{ }^{{ }^{\mathrm{min}}} \leq \mathrm{Q}_{\mathrm{Gi}} \leq \mathrm{Q}_{\mathrm{Gi}}{ }^{\max } \quad \mathrm{i}=1, \ldots . \mathrm{NG}
\end{aligned}
$$

\section{PROPOSED METHODOLOGY Real coded Genetic Algorithm}

Real Coded Genetic Algorithms are computerized search and optimization algorithms based on the mechanics of natural genetics and natural selection. In RCGA, variables are used directly, binary strings are not used. Holland proposed this algorithm in the 60's and 70's. This algorithm is used in this study for the optimal placement of SVC. It has desirable characteristics as an optimization tool and offers significant advantages over traditional methods. It is an evolutionary computing and excellent method for searching optimal solution in a complex problem [11]. It may be used to solve a combinatorial optimization problem. GAs starts with random generation of initial population which represents possible solutions of the problem. Meta-heuristic algorithm- based engineering optimization methods, including GA, have occasionally overcome several deficiencies of conventional numerical methods. This algorithm helps us to reach to a near global optimum solution. A new set of string (i.e. chromosomes) is produced in each iteration of GA with improved fitness by using genetic operators[12]. The first step in the solution of an optimization problem using GA is the encoding of the variables. In working principle of GA, an unconstrained optimization problem is considered firstly. The maximization problem is given in equation (17).

Maximize $F(x), \quad x_{i}^{(L)}<x_{i}<x_{i}^{(U)}$

Where,

$\mathrm{i}=1,2,3 \ldots \ldots, \mathrm{N}$

The working of GA is completed by performing the following methods.

\subsection{Coding}

In order to use GA, variables $x_{i}$ 's are coded in string structure firstly. The coding of variables is not necessary here. GA is directly used on the variables themselves in some studies.

\subsection{Fitness Function}

In this method, fitness function $\mathrm{F}(\mathrm{x})$ is derived firstly from the objective function and used in successive genetic operations. In the case of maximization problem, fitness function can be same as the objective function or $\mathrm{F}(\mathrm{x})=\mathrm{f}(\mathrm{x})$. In case of minimization problem, fitness function is equivalent to maximization problems such that optimum point remains same.

\subsection{Operators}

The operation of GA begins with a population of random strings like design or decision variables. Then each string is evaluated to find the fitness value and population is then operated by operators. The operators used in this algorithm are selection, crossover and mutation.

5.3.1 Reproduction- In this process, chromosomes are choosing from the population to contribute in crossover and mutation processes which lead to produce new offspring. This process is usually based on the fitness value, in which parents are selected according to their fitness. The individual that has high fitness value will have more chance to be selected. In this we select the best chromosomes from the parents in hope that combining them will produce better offspring chromosomes. Hence, this process is responsible for transferring the individuals that have higher fitness to the new population. From the initial population, chromosomes are selected randomly to be parents for reproduction.

5.3.2 Crossover- This operator is main distinguishing feature of a GA. By this operator, the information of two parents' genotypes is merged to produce one or two offspring genotypes. After this process, the new population may contain better individuals. It is a stochastic operator, where a random appointing of crossover sites in the individual strings is implemented. The values following the selected cross site are swapped between the two strings. The crossover process will/will not occur depending on the value of crossover probability.

5.3.3 Mutation- Mutation is the process of replacing the gene value (allele) by another. The new value usually is a random value. This operator maintains diversity in the population. The aim of this process is to explore the whole search space to prevent the algorithm to be trapped in a local minimum. It can be noted that if the mutation probability is large, the search will be faster, while the diversity of population will be less. This leads to more convergence toward some local optima.[13]

There are four ways which makes GAs differs from other optimization:

1) GA is working with a coding of the parameter set.

2) GA search from a population of points, not a single point so it can provide globally optimal solutions.

3) GA use only objective function information, not derivatives or other auxiliary knowledge so it can deal with the non-smooth, non-continuous and non differentiable functions.

4) GA uses probabilistic transition rules, not deterministic rules [14][15].

The figure shows the general flowchart of GA for placement of SVC. 


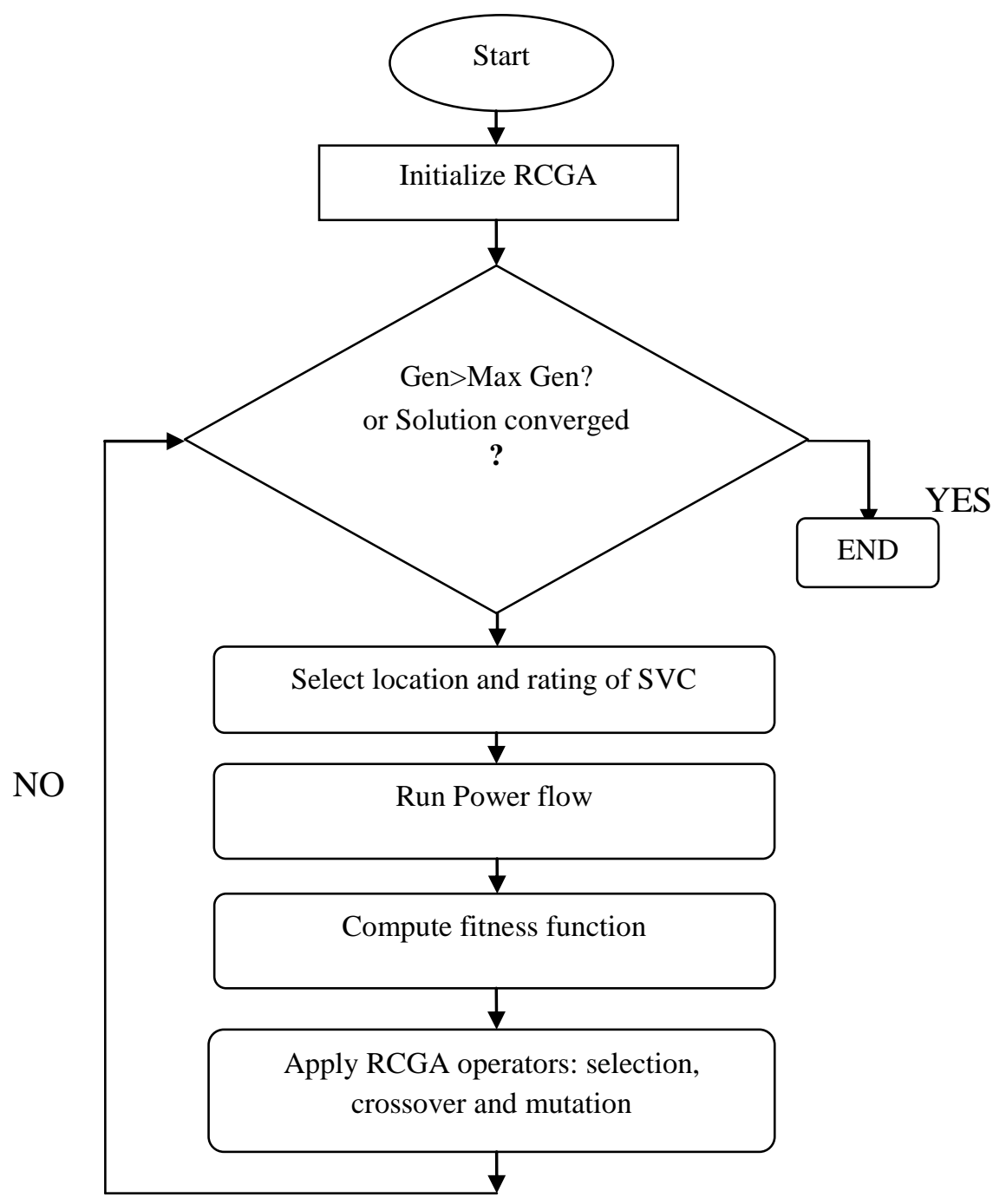

Fig 2: Flowchart for RCGA

\section{RESULTS}

The proposed method is implemented on IEEE 30-bus system shown in Fig.5. The test bus system consists of 1 slack bus, 5 generator buses, 24 load buses. The first step is to determine suitable locations for the SVC based on their primary function. In this study, genetic algorithm is used to optimally locate SVC in the power system. To determine the optimal location and size of SVC devices in the network, the proposed real coded genetic algorithm has been implemented. Table 1 shows the results without SVC. Table. 2 shows the various objective functions after installation of the SVC devices. It is observable from table that the SVC placement by using the genetic algorithm leads to lower power loss, SVC cost, and slightly less voltage deviation. The SVC of different ratings and their respective optimal location as computed from the developed GA program are shown in Table 1. After placing SVC at their respective optimal location the power loss, load bus voltage deviation and installation cost are obtained which are also shown in Table 1. The computed value of power loss is voltage deviation is and cost of SVC is at the optimal location.Table. 3 and table. 4 shows the voltage profile with and without SVC. Fig. 3 shows the convergence characteristics for SVC placement between generation and cost. Voltage profile at line outage 36 without and with SVC is shown in figure.4. The voltage profile at critical load is shown in figure.5.
Table 1. Power loss and voltage deviation without SVC

\begin{tabular}{|c|c|c|c|}
\hline S.No & Cases & Power loss & $\begin{array}{c}\text { Voltage } \\
\text { deviation }\end{array}$ \\
\hline 1. & Line outage 36 & 0.2002 & 0.9659 \\
\hline 2. & Critical load & 0.5378 & 3.0981 \\
\hline
\end{tabular}

Table 2. Results after placement of SVC

\begin{tabular}{|c|c|c|c|c|}
\hline S.No. & $\begin{array}{c}\text { Optimal } \\
\text { location }\end{array}$ & $\begin{array}{c}\text { Voltage } \\
\text { Power } \\
\text { loss } \\
\text { (P.u.) }\end{array}$ & $\begin{array}{c}\text { deviation } \\
\text { (P.u.) }\end{array}$ & $\begin{array}{c}\text { Installation } \\
\text { Cost(\$) }\end{array}$ \\
\hline 1. & 4 & 0.1993 & 1.1694 & 2334.00 \\
\hline
\end{tabular}




\subsection{Contingency conditions}

6.1.1 Line outage 36

The voltage profiles for line outage without and with SVC are given in the table below:

Table 3. Voltage profile at line outage 36

\begin{tabular}{|c|c|c|c|}
\hline Bus no. & $\begin{array}{c}\text { Base case } \\
\text { voltage }\end{array}$ & $\begin{array}{c}\text { LO } 36 \\
\text { without SVC }\end{array}$ & $\begin{array}{c}\text { LO 36 } \\
\text { with SVC }\end{array}$ \\
\hline 1. & 1.0600 & 1.0600 & 1.0600 \\
\hline 2. & 1.0430 & 1.0430 & 1.0430 \\
\hline 3. & 1.0215 & 1.0201 & 1.0327 \\
\hline 4. & 1.0129 & 1.0112 & 1.0264 \\
\hline 5. & 1.0100 & 1.0100 & 1.0100 \\
\hline 6. & 1.0121 & 1.0115 & 1.0126 \\
\hline 7. & 1.0034 & 1.0031 & 1.0038 \\
\hline 8. & 1.0100 & 1.0100 & 0.9966 \\
\hline 9. & 1.0510 & 1.0461 & 1.0542 \\
\hline 10. & 1.0444 & 1.0354 & 1.0513 \\
\hline 11. & 1.0820 & 1.0820 & 1.0820 \\
\hline 12. & 1.0574 & 1.0530 & 1.0907 \\
\hline 13. & 1.0710 & 1.0710 & 1.0829 \\
\hline 14. & 1.0424 & 1.0353 & 1.0709 \\
\hline 15. & 1.0378 & 1.0270 & 1.0602 \\
\hline 16. & 1.0447 & 1.0382 & 1.0670 \\
\hline 17. & 1.0391 & 1.0309 & 1.0508 \\
\hline 18. & 1.0279 & 1.0177 & 1.0451 \\
\hline 19. & 1.0253 & 1.0154 & 1.0393 \\
\hline 20. & 1.0293 & 1.0196 & 1.0415 \\
\hline 21. & 1.0321 & 1.0182 & 1.0356 \\
\hline 22. & 1.0327 & 1.0173 & 1.0350 \\
\hline 23. & 1.0272 & 1.0045 & 1.0336 \\
\hline 24. & 1.0216 & 0.9835 & 1.0068 \\
\hline 25. & 1.0189 & 0.9246 & 0.9498 \\
\hline 26. & 1.0012 & 0.9051 & 0.9308 \\
\hline 27. & 1.0257 & 0.8999 & 0.9259 \\
\hline 28. & 1.0107 & 1.0153 & 1.0130 \\
\hline 29. & 1.0059 & 0.8770 & 0.9037 \\
\hline 30. & 0.9945 & 0.8637 & 0.8909 \\
\hline
\end{tabular}

\section{Critical load}

The voltage profiles at critical load without and with SVC are given in table below:

Table 4. Voltage profile at critical load

\begin{tabular}{|c|c|c|}
\hline Bus no. & Without SVC & With SVC \\
\hline 1. & 1.0600 & 1.0600 \\
\hline 2. & 0.9686 & 1.0187 \\
\hline 3. & 0.9259 & 1.0122 \\
\hline 4. & 0.9004 & 1.0047 \\
\hline 5. & 0.8685 & 0.9577 \\
\hline 6. & 0.8875 & 0.9978 \\
\hline 7. & 0.8648 & 0.9685 \\
\hline 8. & 0.8875 & 1.0100 \\
\hline 9. & 0.9116 & 1.0368 \\
\hline 10. & 0.8905 & 1.0242 \\
\hline 11. & 0.9634 & 1.0820 \\
\hline 12. & 0.9179 & 1.0663 \\
\hline 13. & 0.9532 & 1.0710 \\
\hline 14. & 0.8904 & 1.0406 \\
\hline 15. & 0.8813 & 1.0304 \\
\hline 16. & 0.8936 & 1.0376 \\
\hline 17. & 0.8820 & 1.0201 \\
\hline 18. & 0.8626 & 1.0095 \\
\hline 19. & 0.8572 & 1.0020 \\
\hline 20. & 0.8641 & 1.0063 \\
\hline 21. & 0.8682 & 1.0056 \\
\hline 22. & 0.8691 & 1.0065 \\
\hline 23. & 0.8605 & 1.0079 \\
\hline 24. & 0.8478 & 0.9907 \\
\hline 25. & 0.8463 & 0.9857 \\
\hline 26. & 0.8136 & 0.9580 \\
\hline 27. & 0.8613 & 0.9961 \\
\hline 28. & 0.8800 & 0.9963 \\
\hline 29. & 0.8236 & 0.9645 \\
\hline 30. & 0.8018 & 0.9463 \\
\hline
\end{tabular}




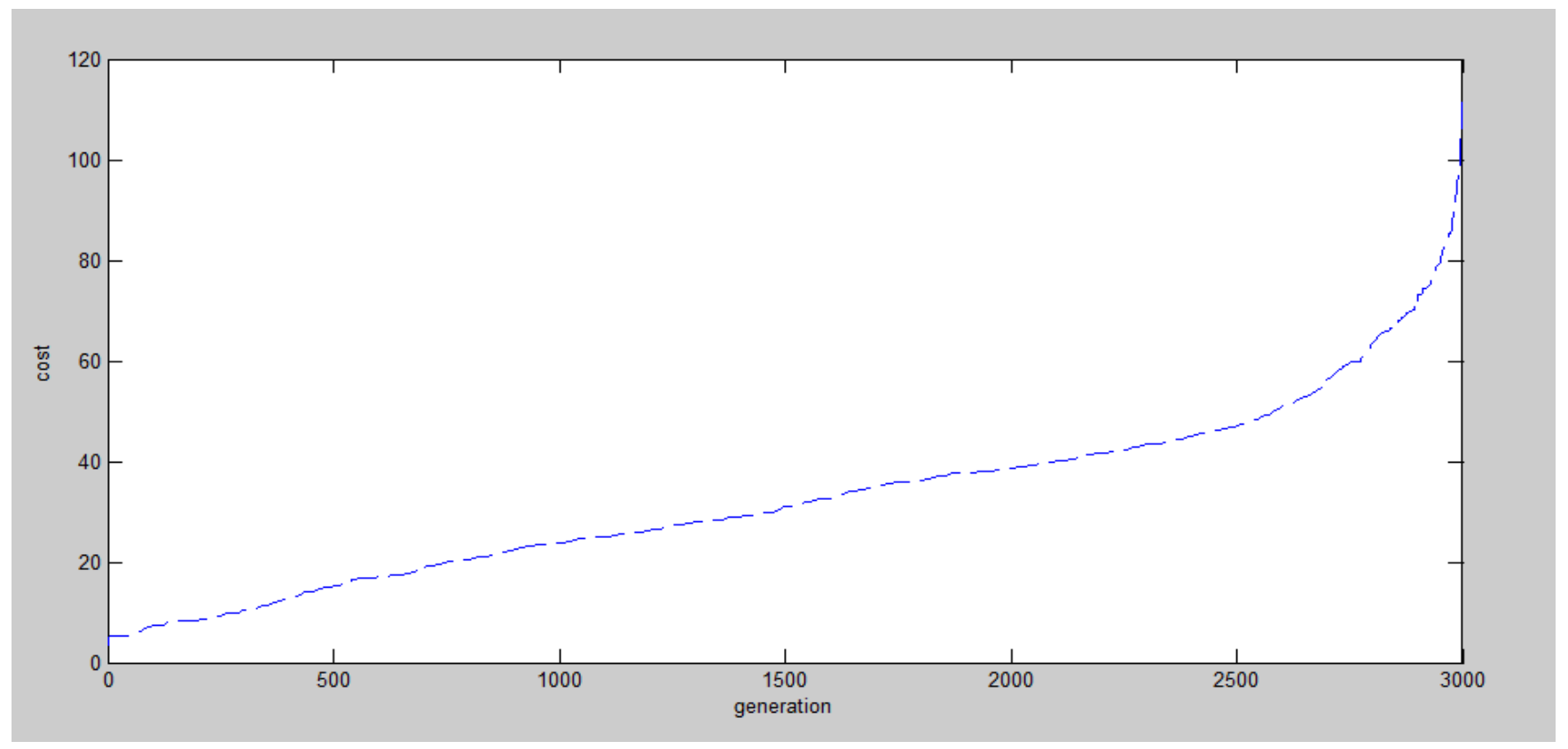

Fig.3: Convergence characteristics for placement of SVC

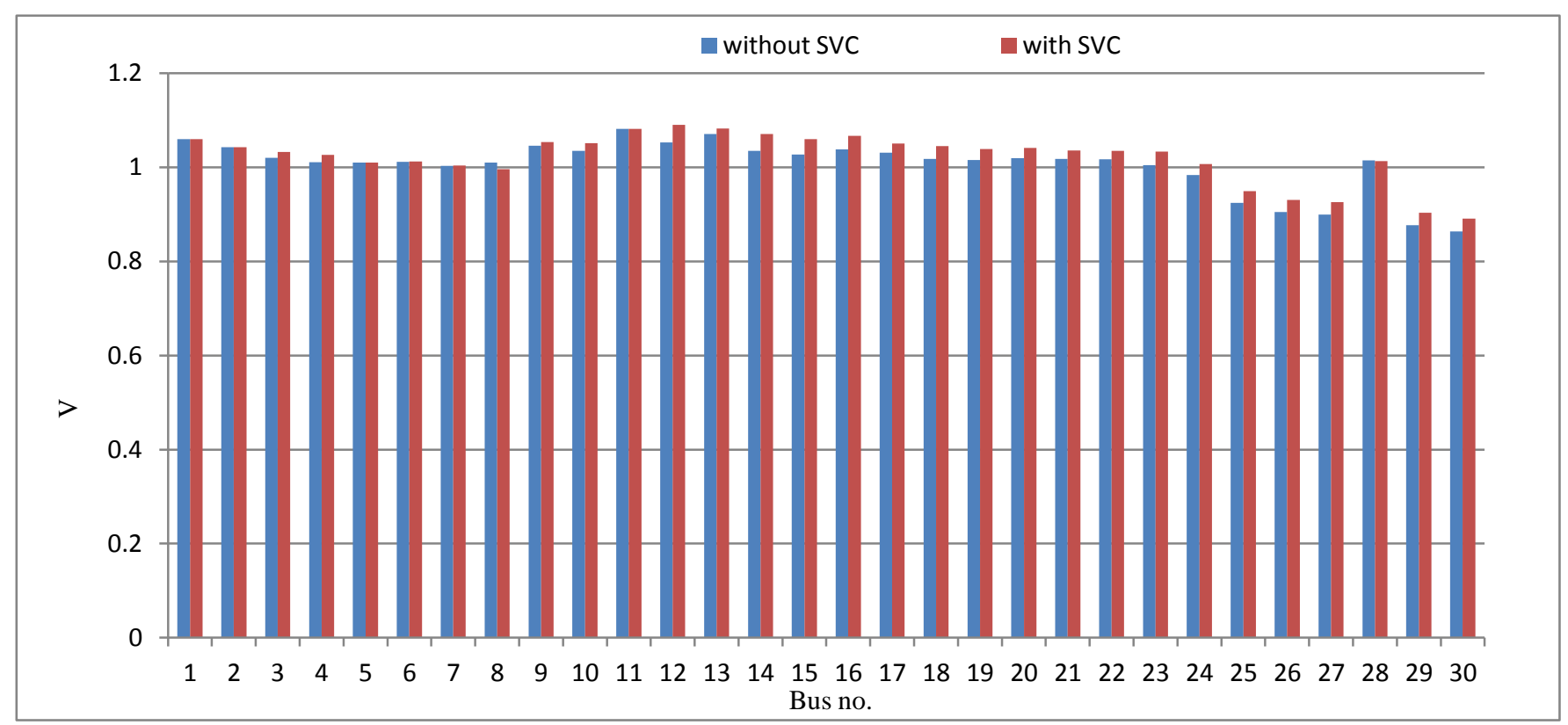

Fig 4: Convergence characteristics for voltage profile at line outage 36 


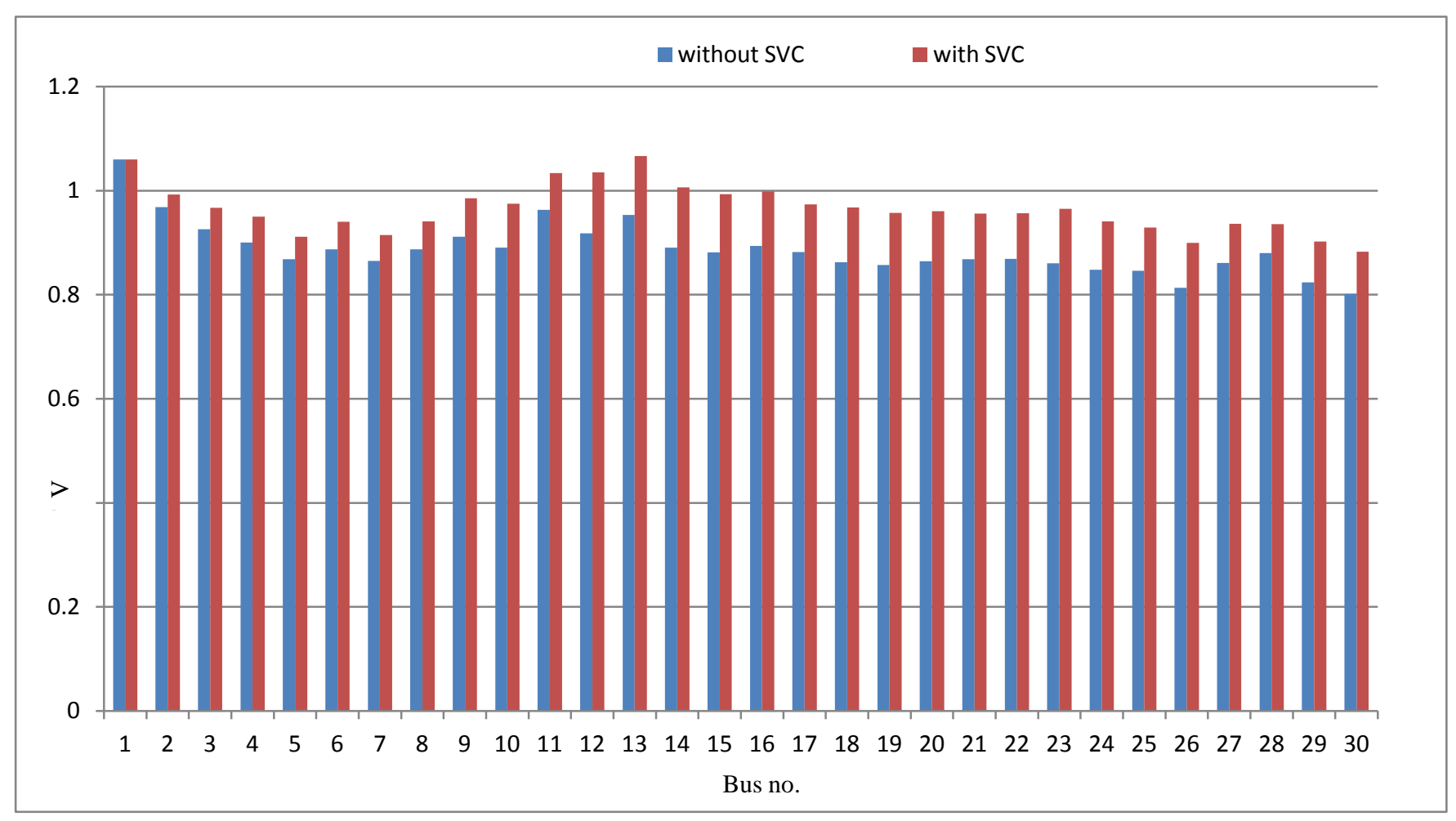

Fig. 5: Convergence characteristics for voltage profile at critical load

\section{CONCLUSION}

In this paper an algorithm for minimizing power loss, voltage deviation and installation cost has been proposed. The application of the real coded genetic algorithm as a meta heuristic optimization method for determining the optimal location of SVC device in a bus system has been presented. The proposed multi-objective real coded genetic algorithm has been implemented on the IEEE 30-bus system and the obtained results showed that the real coded genetic algorithm gives greater reduction in power loss, voltage deviation and total SVC costs. The results clearly indicate the efficiency of the proposed genetic algorithm while it determines the optimal location and sizing of the SVC devices. This algorithm is practical and easy to implement in large-scale power systems.

\section{REFERENCES}

[1] J. G. Singh, S. N. Singh, S. C. Srivastava, "An Approach for Optimal Placement of Static VAr Compensators Based on Reactive Power Spot Price", IEEE Transactions On Power Systems, Vol. 22, No. 4, November 2007.

[2] Pavlos S. Georgilakis ,Peter G. Vernados, "Flexible AC Transmission System Controllers: An Evaluation" in Materials Science Forum, Switzerland, 2011.

[3] Shishir Dixit, Ankita Singh, "An Overview of Placement of TCSC For Enhancement of Power System Stability" in IEEE International Conference on Computational Intelligence and Communication Networks (CICN2014), Nov 08-10, 2014, JRNRV University, Udaipur.
[4] Ankita Singh, Shishir Dixit, "Placement of SVC Using Genetic Algorithm for Enhancement of Power System Stability" in National Conference IIEE-15 organized by Department of Elelctrical Engineering on Feb 10-11, 2015, MITS Gwalior

[5] Siti Amely Jumaat, Ismail Musirin, Muhammad Murtadha Othman, Hazlie Mokhlis, "Transmission Loss Minimization Using SVC Based on Particle Swarm Optimization" in ISIEA-2011, September 25-28, 2011, Johor, Malaysia.

[6] Ankita Singh, Shishir Dixit, "GA Based Optimal Placement of SVC for Minimizing Installation Cost and Voltage Deviations" in International conference on Emerging Trends in Computer Science \& Applications (ETCSA-2015) on April 7-8, 2015, RJIT Tekanpur.

[7] S.Sakthivel, Dr.D.Mary, R.Vetrivel, V.Senthamarai Kannan, "Optimal Location of SVC for Voltage Stability Enhancement under Contingency Condition through PSO Algorithm" in International Journal of Computer Applications (0975 - 8887),Tamil Nadu, India.

[8] Reza Sirjani, Azah Mohamed, Hussain Shareef, "Optimal placement and sizing of Static Var Compensators in power systems using Improved Harmony Search Algorithm" Kebangsaan Malaysia (UKM).

[9] B.Chandra sekhar, Dr.N Visali, "Optimal Placement of SVC with Cost Effective Function Using Particle Swarm Optimization" in International Journal of Emerging Trends in Engineering Research JNTUACE Pulivendula, India. Vol. 1 No.2, October, 2013. 
[10] M.A.Abido, "Optimal Power Flow Using Particle Swarm Optimization".

[11] Mugdha Bhandari, Sri.G.N.Madhu, "Genetic Algorithm Based Optimal Allocation of SVC for Reactive Power Loss Minimization in Power Systems" in International Journal of Electrical, Electronics and Data. Communication, Vol-2, Oct.-2014, Davangere, Karnataka.

[12] K. Vijayakumar, Dr. R. P. Kumudinidevi, “A New Method For Optimal Location Of Facts Controllers Using Genetic Algorithm" in Journal of Theoretical and Applied Information Technology.

[13] H. A. Hassonny. K. Pfeiffer, Firas M. Tuaimah, “ V/VAR Control for the Iraqi National SHV Grid by Optimum Placement of SVC using Genetic Algorithm" in International Journal of Computer Applications (0975 - 8887) Volume 66, No.12, March 2013

[14] El. M M. Metwally, El. AA. Emary, El. FM. Bendary and M. I. Mosaad, " Optimal allocation of FACTS devices inpower system using genetic algorithms," in Proc. MEPCON 2008, IEEE conference.

[15] Shishir Dixit, Laxmi Shrivastava, Ganga Agnihotri, "Optimal Location and Sizing of STATCOM for minimizing power loss and improving voltage profile using GA" has been accepted for publication in International Journal of Communication Systems and Networks.

[16] Shishir Dixit1, Laxmi Srivastava, Ganga Agnihotri, "Optimal Allocation of SVC for Minimization of Power Loss and Voltage Deviation using NSGA-II" in International Journal of Advanced Science and Technology, Vol.71, 2014.

[17] R. Benabid, M. Boudour, "Optimal Location and Size of SVC and TCSC for Multi-objective Static Voltage Stability Enhancement" Algiers (Algeria).

[18] Shishir Dixit, Laxmi Shrivastava, Ganga Agnihotri, Rahul Dubey, "Ideal Location of Shunt FACTS Devices Using Heuristic Optimization Techniques: A Litrature Survey".
[19] S.Chansareewittaya, P.Jirapong, "Power Transfer Capability Enhancement with Multitype FACTS Controller Using Particle Swarm Optimization," in Proc IEEE TENCON 2010.

[20] Shishir Dixit, Laxmi Srivastava, Ganga Agnihotri, “ Minimization of Power Loss and Voltage Deviation by SVC Placement Using GA" in International Journal of Control and Automation, Vol. 7, 2014.

[21] Shishir Dixit, Ganga Agnihotri, Laxmi Srivastava, "Optimal SVC Placement in Electric Power System Using NSGA-II" in International Journal of Control and Automation, Vol. 7, 2014.

[22] N. Suresh, Kiran Kumar Kuthadi, "Enhancement of Voltage Stability through Optimal Placement of Facts Controllers in Power Systems" in American Journal of Sustainable Cities and Society, Vol.1 July 2012 in Nagpur, Maharashtra, India.

[23] S.A.Jumaat, I.Musirin, M. M. Othman, H.Moklis, "Computational Intelligence Based Technique in Multiple Facts Devices Installation for Power System Security" Vol. 46, No.2 in Journal of Theoretical and Applied Information Technology, December 31st, 2012, Johor, Malaysia.

[24] Shraddha Udgir, Sarika Varshney, Laxmi Srivastava Optimal Placement and Sizing of SVC for Voltage Security Enhancement" in International Journal of Computer Applications, Vol 32, No.6, October 2011.

[25] M. Saravanan et al. "Application of particle swarm optimization technique for optimal location of FACTS devices considering cost of installation and system loadability", Electric Power System Research 77 (2007) 276-283.

[26] K.Vijayakumar, Dr. R. P. Kumudinidevi, “A New Method For Optimal Location Of Facts Controllers Using Genetic Algorithm" in Journal of Theoretical and Applied Information Technology, 2005 - 2007.

[27] A. Kazemi, and B. Badrzadeh, "Modeling and Simulation of SVC and TCSC to Study their Limits on Maximum Loadability Point," Electrical Power and Energy Systems, Vol. 26, pp. 619-626, Apr. 2004. 